\title{
MYOCARDIAL INFARCTION AFTER A MAZE PROCEDURE FOR IDIOPATHIC ATRIAL FIBRILLATION
}

Taijiro Sueda, MD, Hiroo Shikata, MD, Norimasa Mitsui, MD, Hideyuki Nagata, MD, and Yuichiro Matsuura, MD, Hiroshima, Japan

The Cox maze procedure is an effective means to treat intractable atrial fibrillation ${ }^{1}(\mathrm{AF})$, as well as chronic $\mathrm{AF}$ with mitral valve disease. ${ }^{2}$ In this procedure, cryoablation is used to avoid coronary arterial damage at the right atrioventricular groove and at the posterior mitral anulus. ${ }^{1}$ We report here a case of acute myocardial infarction 3 months after a maze procedure. In this case, the cryoablation may have caused coronary arterial damage, thus resulting in myocardial infarction and mitral valve insufficiency owing to papillary muscle dysfunction.

From the Department of Surgery, Hiroshima University, School of Medicine, Hiroshima, Japan.

Received for publication Oct. 30, 1995; accepted for publication Oct. 31, 1995.

Address for reprints: Taijiro Sueda, MD, Department of Surgery, Hiroshima University, School of Medicine, 1-2-3 Kasumi Minami-Ku, Hiroshima, 734 Japan.

J Thorac Cardiovase Surg 1996;112:549-50

Copyright (C) 1996 by Mosby-Year Book, Inc.

$0022-5223 / 96 \$ 5.00+0 \quad \mathbf{1 2 / 5 4 / 7 0 3 2 4}$
Case report. A 68-year-old man had had several episodes of peripheral arterial emboli, as well as cerebral infarction. A transesophageal echocardiogram revealed a large thrombus in the left atrial appendage and an enlarged left atrium, despite the absence of any valvular disease. Electrocardiograms had revealed chronic AF during the past 6 years. Preoperative coronary cineangiograms showed no stenoses in the right or left coronary arteries (Fig. 1), and peripheral arterial angiograms showed embolic obstruction of the left posterior tibial and right anterior tibial arteries. A diagnosis of idiopathic AF with a large left atrial thrombus and systemic embolization was made.

A maze procedure combined with a left atrial thrombectomy was then performed. During this procedure, cryoablation $\left(-60^{\circ} \mathrm{C}\right.$ for 2 minutes) was applied to the right atrioventricular groove and the posterior mitral anulus instead of a direct incision to avoid coronary arterial injury. After the completion of the maze procedure, a spontaneous sinus rhythm appeared and the postoperative course was uneventful except for one episode of paroxysmal atrial tachycardia. Transesophageal
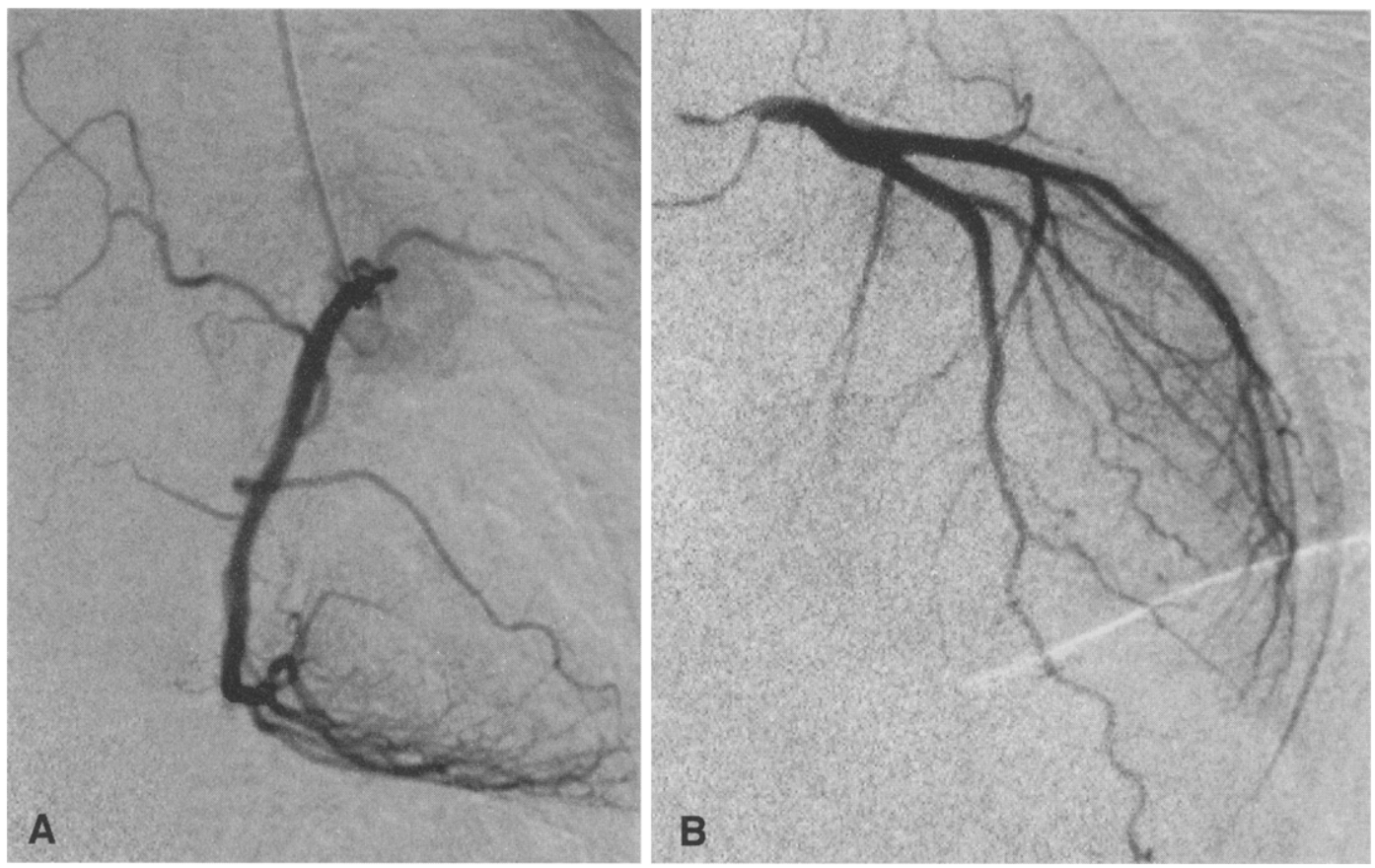

Fig. 1. Preoperative coronary cineangiograms revealed no stenosis in either coronary artery. A, Right coronary artery. B, Left coronary artery. 

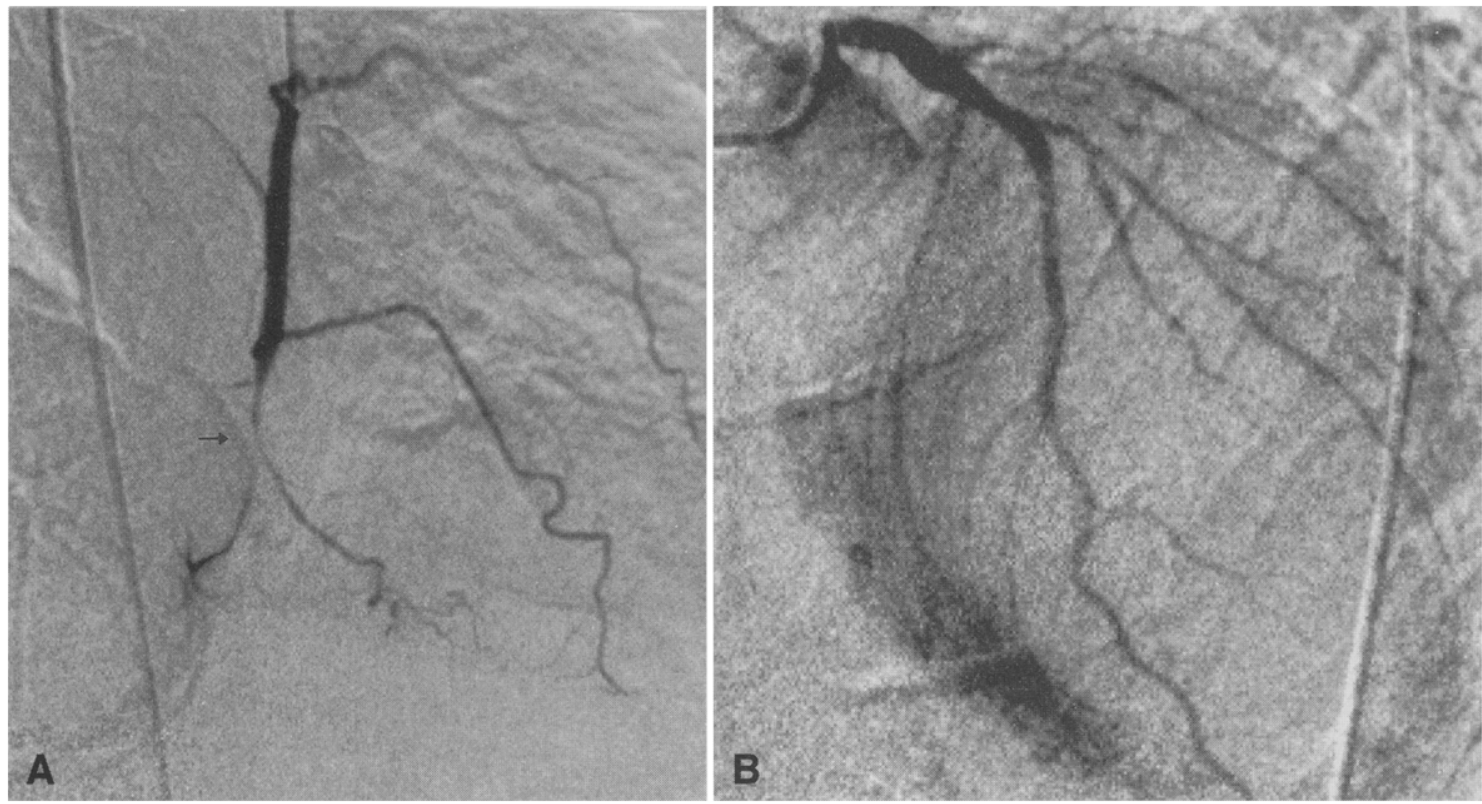

Fig. 2. Coronary cineangiography after the maze procedure. The coronary cineangiograms reveal distal occlusion of the right coronary artery (A) (segment 2, arrow) (seg. 2) and of the left circumflex coronary artery (B) (segment 12, 90\% stenosis; segment 13, 99\% stenosis).

echocardiography did not show any signs of left ventricular asynergy or left atrial thrombus. He was discharged 24 days after the operation.

The patient was placed on a regimen of low-dose warfarin sodium (2 $\mathrm{mg} /$ day) and dysopiramide $(200 \mathrm{mg}$ / day). However, he had an episode of abrupt dyspnea and tachycardia 3 months after the maze operation. Electrocardiograms showed ST segment depression in leads II, III, aVF, and $V_{4}$ to $V_{6}$. Echocardiograms demonstrated akinesis of the posterior left ventricular wall, with severe mitral regurgitation caused by prolapse of the anterior mitral leaflet. Coronary cineangiograms revealed an obstruction of the right coronary artery (segment 2) and severe stenosis of the left circumflex coronary artery (segments 12 and 13) (Fig. 2). These sites of coronary obstruction matched exactly the site on which cryoablation had been performed. One month after the onset of the myocardial infarction, a coronary arterial bypass was performed by grafting to the left circumflex artery, and a mitral valve replacement was also performed with preservation of the anterior and posterior leaflets. The operations were successful, and he was discharged from the hospital 35 days after the second operation.

Discussion. $\operatorname{Cox}^{1}$ described the maze procedure as a radical treatment for AF. Kosakai and his colleagues ${ }^{2}$ reported a modification of the original maze procedure, in which cryoablation was used more frequently to avoid injuries to the sinus nodal arteries. They also emphasized the superiority of this treatment for chronic AF with mitral valve disease. However, both procedures required cryoablation to the right and left posterior atrioventricular grooves. We used the maze procedure for idiopathic AF and the left atrial maze procedure ${ }^{3}$ for chronic AF with mitral valve disease. This was the first case of myocardial infarction after cryoablation to the atrioventricular anulus in our clinical experience of 35 maze procedures and 34 cases of endocardial interruption of the accessory pathway in Wolff-Parkinson-White syndrome. To our knowledge, this is the first report of a myocardial infarction after the maze procedure. However, there is the theoretic possibility of coronary arterial endothelial injury during cryoablation of the atrioventricular anulus. In this case, the sites of the coronary arterial obstruction matched exactly those sites on which cryobalation had been applied. Although myocardial infarctions are rare after the maze procedure, coronary arterial injury may occur after careful cryoablation of the atrioventricular groove and may result in a myocardial infarction.

\section{REFERENCES}

1. Cox JL. The surgical treatment of atrial fibrillation. IV. Surgical technique. J Thorac Cardiovasc Surg 1991;101:584-92.

2. Kosakai Y, Kawaguchi A, Isobe F, Sasako Y, Nakano K, Eishi $\mathrm{K}$, et al. Cox maze procedure for chronic atrial fibrillation associated with mitral valve disease. J Thorac Cardiovase Surg 1994;108:1049-55.

3. Brodman RF, Frame R, Fisher JD, Kim SG, Roth JA, Ferrick KJ. Combined treatment of mitral stenosis and atrial fibrillation with valvuloplasty and a left atrial maze procedure (letter). J Thorac Cardiovasc Surg 1994;107:622. 